\title{
Tangible Resources and Performance of County Health Services in Kenya
}

\author{
Dr. Okoth, P.J. \\ Jaramogi Oginga Odinga Teaching and Referra Hospital \\ Kenya. \\ Machuki, V.N, PhD \\ School of Business, University of Nairobi \\ Kenya.
}

\begin{abstract}
This paper investigated the influence of tangible resources on the performance of county health services in Kenya using resource based view approach. The research collected secondary data of all counties from ministry of health records and reports regarding current tangible resources owned by county health services departments as well as data on performance indicator achievements (over the last three years) then analyzed the relationship between the two variables to identify tangible resources associated and most useful to performance. The findings of this study confirm that there is tangible resource heterogeneity across Kenya's county health departments that explain performance indicator achievement differentials. Not all resources contribute to superior performance. It's just some specific resources that are responsible for superior performance. These are the critical strategic resources that the study suggests may be currently needed for improved performance in given health indicators. The study makes a recommendation for an improved approach that uses a composite performance index, a single measure of overall health performance, upon which resources are evaluated. This study that relates health resources with performance has the potential of advancing resource based theory from being a mere theoretical framework to being a practical framework for practicing managers, policy makers and planners in the health sector.
\end{abstract}

Keywords: Tangible Resource, Resource Based View, Organizational Performance

\section{Introduction}

One of the major objectives of strategic management is to provide scholars and practitioners with management thoughts, approaches, and tools to enable firms formulate and implement strategies that generate competitive advantage. According to Grant (2005), the critical requirement for a firm's success is its ability to establish competitive advantage. Barney (2007) defines competitive advantage as the ability of an organization to design, produce, and market products or services that are superior to those of competing firms in the same industry based on price and non price qualities. Grant (2005) noted that a firm possesses competitive advantage over its rivals in the same market when it earns a persistently higher rate of profit. Perhaps because competitive advantage is difficult to measure, a series of studies have sought to link strategic resources and performance.

According to Barney (2007), most strategic management researchers agree that internal resources owned by an organization may provide it with a more appropriate strategic choice on how to compete in the external environment and provide an indication of the level of performance expected. The extent to which internal resources can translate into superior performance in specific organizations is still not well understood, especially under deprived conditions. Organizations differ in terms of amount and quality of strategically relevant resources and how they are utilized but it is still not clear how these differences can lead to competitive advantage and superior performance. Collis and Montgomery (1995) have argued that no two organizations have the same assets, skills, organization culture or same combination of resources in the same competitive environment at one point in time to be able to perform their activities perfectly in the same manner. There will always be differences in terms of quality, quantity, combination and utilization of resources across these health organizations. Several contextual factors directly or indirectly affect the competitive strength of individual organizations and this poses a challenge in identifying specific resources that are relevant to strategic objectives and the extent to which resources can translate into superior performance. 
Health services in Kenya fall under public and private sector organizations that are directly under the control of the government through the ministry of health. The sector is subdivided into medical services, public health and sanitation, and research subsectors. The Kenya Health Sector Policy (KHSP, 2012-2030) offers the overall direction for the health sector. It orientates the sector to Kenya vision 2030 besides recognizing international obligations such as Millennium Development Goals (MDGs). To achieve the policy goal and broad objectives, KHSP (2012-2030) through Kenya Essential Package for Health (KEPH) identifies and defines four tiers and five cohorts around which health care service delivery is organized. The four tiers are the community as tier one, dispensaries and health centers as tier two, county hospitals as tier three and national referral hospitals and research institutions as tier four. County health services is a county department carrying out devolved functions under Schedule 4 of the Constitution of Kenya and include responsibilities such as overseeing clinical services, preventive and promotion of health and health planning (Constitution of Kenya, 2010). These counties not only compete for scarce resources from the national and county governments, donor agencies and other partners such as NHIF but also from paying patients as the main sources of funding and therefore need to meet acceptable standards of performance in order to attract, maintain and improve stakeholders support.

There are marked differences across Kenya's counties in terms of resource endowment in the county health service body, an agency or organization mandated to provide health services to the county population. These organizations possess a wide range of resources that may have direct or indirect impact on their performance depending on how they are utilized to generate value. County health services organizations just like other organizations are heterogeneous and cannot be considered identical in terms of strategically relevant resources. County health services can only attract paying patients and support from stakeholders if they meet acceptable standards of performance. County health managers are faced with challenges such as which area they currently need to prioritize and invest in so as to have superior impact on performance in areas of national and county concerns. Employees in the health sector have always attributed health sector woos to inadequate infrastructure, equipments and key workforce shortages among other tangible inadequacies.

For county health services in Kenya, competitive advantage means providing better quality health care and services that lead to higher outcome than competing services from other counties thus attracting support and more funding from the two governments and other stakeholders. The growing concern among health managers and planners is how to identify specific resources that are currently critical to performance and the best way to allocate and productively use available scarce resources to achieve quality performance. Most county health services in Kenya have registered varying levels of performance over some past years with some recording fluctuating performance while some have consistently indicated an upward trend. Since there are marked differences in resource endowment across counties in terms of quantity, quality and how they are used, it is not clear whether there is any link between resources and performance in county health services in Kenya.

As much as existing literature has reported close links between tangible and intangible resources and performance in organizations, most of the researches have focused on business organizations and even so, business organization outside Africa. There are very few literatures focusing on local organizations as far as resources and performance is concerned. Liu, Timothy and Gao (2010) reviewed RBT approaches as used in banking industry and observed that the relationship between resources, strategy and performance when explored further could be a useful analysis tool. It recommended that further studies be done to establish the role of tangible and intangible resources in industries such as banking in which sustainable competitive advantage are rare.

Tuan and Takayashi (2009) investigated the link between resources, organizational capabilities and performance of Vietnams supporting industries and reported positive links between groups of resources, capabilities and performance. Gruber, Heinmann, Bretel and Hangeling (2010) examined configuration of resources, capabilities and performance in technology ventures and recommended further research on the contribution of tangible and intangible resources on performance of organizations operating in specific industries. Adero (2012) studied the influence of tangible and intangible resources on performance of public secondary schools in Bondo District, Kenya, and reported close links. According to the reviewed literature, no known study has been done on the influence of tangible resources on the performance of county health services in Kenya. The objective of this research was to establish the influence of tangible resources on the performance of county health services in Kenya. 
The findings in this study are expected to contribute to theory building since the study assessed those findings against other empirical support for what is argued to be one of the most important widely accepted theories of strategic management, the RBT (Newbert, 2007). The findings of this study can improve the understanding of policy makers, planners and health managers in the ministry of health and county governments regarding the role of tangible resources on health performance. This study can help health planners and health managers practice evidence based planning. Investing in resources which do not produce results is considered wastage of scarce resources. This study can help in projecting results thus helping in setting realistic targets in performance areas. Health facility managers may benefit through discovery of critical resources that have direct impact on facility and county health performance. This may also help them embrace evidence based performance planning in their institutions.

\section{Literature Review}

Understanding why some organizations outperform others is a central goal of strategic management research. Resource based theory (RBT) and Dynamic capability theory (DCT) have emerged as key perspectives guiding inquiry into the determinants of organizational performance (Crook, Ketchen, Combs and Tood, 2008; Barney, 2007). RBT asserts that an organization achieves competitive advantage over others because it either has resources and capabilities that others do not have or others have difficulty in obtaining (Johnson et al, 2008). Penrose (1959) views organizations as bundles of productive resources and capabilities which can be used to generate competitive advantage and superior performance. DCT, an offshoot from RBT (Crook et al, 2008) emphasizes resource development and renewal as a source of sustainable competitive advantage. It posits that for firms to succeed they must have the ability to integrate, build and reconfigure internal and external competencies to address rapidly changing environment (Teece, 2000). The two theories provide the knowledge base for studying the relationship between resources, strategy development and choice, and performance.

Many empirical findings support the relationship between resources and performance within the framework of RBT and DCT. Discordant findings however few, have been reported in empirical studies. Galbreath and Calvin (2004) discovered that while RBT largely associates firm performance with intangible resources, the association may not always hold true empirically. But this is explained away by the fact that the strength of some resources may be dependent upon interactions or combinations with other resources and therefore no single resource becomes the most important to firm performance. This problem may be brought about by the unit of analysis (Barney, 2007). Most contributions within the RBT take the individual resource as the relevant unit of analysis to study competitive advantage and performance (Foss, 1998). It ignores the complementarity and co-specialization nature of resources (Foss, 1998). Most researchers have recognized the role of firm based tangible and intangible resources as sources of competitive advantage and superior performance in organizations.

Resources are the basic primary inputs into organizational processes used to develop products or services of value to customers (Grant, 2005). Penrose (1959) describes resources as the components that constitute the firm. She sees firms as bundles of productive resources whose destiny (decline, survival and success) is determined by the administrative framework (interpreted here as organizational design, general management capability and institutional leadership). Resource therefore is a construct. The implication of Penrose observation is that resources can only be understood through unbundling. Unfortunately, this provides scholars with unrestricted space for plethora of definitions and examples that often lead to confusion. Barney (2007) defines resources as all assets, capabilities, competencies, organizational processes, firm attributes and knowledge among others that are controlled and used by an organization to conceive and implement strategies that enhance efficiency and effectiveness in a competitive environment.

According to Pearce and Robinson(2010) resources are organizational assets that form the basic building blocks for organizational performance, that include physical assets such as plant, equipment, location, human assets in terms of number of people, skills and experience and organizational assets that include culture and reputation. Resources can be categorized into tangible(physical and financial) and intangible human and organizational( Grant, 2005).Tangible resources can easily be imitated by the competition and according to Barney(2007) can only lead to competitive parity(average performance) at threshold level or temporary advantage at superior level. For a physical resource to be strategic it should be able to create competitive advantage, it must have the potential or capacity to create services. Physical resources vary widely across organizations in terms of quality, quantity and how they are utilized and therefore may explain performance differentials among firms. 
Still it remains uncertain which physical resources are critical to performance and the extent to which possession of substantial amount of physical resources can translate into superior performance.

Financial resources are the monetary resources an organization controls and include loans, grants, cash balances, debtors, retained earnings, internal financial generating projects and others. Twan et al (2009) observes that financial resources are in most cases limited, expensive, difficult to acquire and manage. Access to reliable sources of funding and ability to generate acceptable returns on invested money will determine ability of an organization to attract more funding from its stakeholders (Barney, 2007). Johnson et al (2008) noted that finance and the manner in which it is managed can be a key determinant of strategic success in organizations. The main issue is to deliver services to the stakeholders that matches or out matches the level of investment. It still remains uncertain however whether substantial amount of financial resources can translate into superior performance.

Firm performance is conceptualized by comparing the willingness of a firm's customers to pay and a firms cost of developing and selling its products or services (Barney, 2007). This difference is known as economic value. Firms that create more economic value than competitors gain competitive advantage and better performance. Those that create the same economic value are said to be at competitive parity. It is the actual result measured against intended goals and objectives.

Organizational performance is an outcome achieved when an organization successfully formulates and implements a value creating strategy which enable customers receive a service or product of value greater than what they are willing to pay for (Barney, 2007).Stakeholders view value creation in terms of more returns compared with an alternative investment of similar risk, the benefit of forgoing an alternative investment of similar risk (Barney, 1991). Superior performance is achieved when the actual outcome achieved exceeds what is expected based on resources invested for the same purpose. This means that the actual value created is greater than expected value, and that it could be a sign of well managed resources.

According to Dessler (2008) as cited in Adero (2012), performance is a collection of work activities, operational efficiencies, effectiveness, their measurements and subsequent outcome attained. Most studies in organizational performance have used both financial and non financial indicators that include profit, turnover, return on investment, return on capital employed, inventory turnover(Porter, 1985).Benchmarking is a performance tool used to determine how an organization compares with the competition in the same industry(Johnson et al, 2008).Benchmarking involves comparing own performance against industry best practices in terms of quality, operational efficiency and effectiveness, time and cost in order to learn how to do things better , faster and cheaper (Adero, 2012).

A trend has emerged whereby the use of balanced scorecard (Kaplan and Norton, 2001) is increasing as a contemporary method in measuring performance. The balanced scorecard analyses both financial and non financial outcomes. It tries to accommodate diverse stakeholder interests and relate performance with strategic objectives. It uses financial measurements that reveal the results of actions already taken and complements this with operational measures such as customer satisfaction, internal process effectiveness and ability to learn and improve the activities that drive future financial outcome. The business process dimension enable managers to evaluate how well the business is running and whether its day to day activities including tasks performed by the workforce support its strategic objectives, based on their mission and vision.

According to Kaplan et al (1992), measuring organizational performance against the needs of its customers can be a pointer towards future performance excellence. As such organizations that are able to derive the best results from this area are likely to achieve future financial benefits and stay ahead of competition, while failure in this area would lead to financial decline. The balanced scorecard not only links performance to short term outcome but also the way in which processes are managed, involving innovation and learning which are perceived to be crucial to long term success. Organizations that achieve continuous success are those that evaluate their performance with respect to formulated goals that match their resource strength, using performance indicators that suit their context (Adero, 2012).Many scholars contend that organizational performance is closely related to amount and quality of tangible and intangible resources within its command.

Most scholars believe that profit differentials among firms in the same industry can be explained in terms of their resource heterogeneity. The acquisition and development of superior organization resources is the most important reason that some organizations are more successful than others (Wernerfelt, 1984; Corner, 1991). Johnson et al (2008) observed that varying levels of performances in organizations can be explained by 28 
differences in amount and quality of resources they possess and the extent to which they use the resources to generate value to customers. Differences in resource endowment may form the basis for superior outcome in organizations but this is not an adequate reason since not all resources owned by organizations are strategically relevant to performance (Peteraf, 1993; Barney 2007).

Barney (2007) states that for a resource to lead to superior performance, it must be valuable to customers, rare, difficult to access, inimitable and non- substitutable for advantage to last. Organizations that stay ahead of others are those that are able to identify specific resources that are critical to strategic goals, acquire or develop and maintain them to generate more value than competitors. According to Newbert (2007), resource heterogeneity, organizing level, and dynamic capabilities are important in explaining organizational performance. Resource heterogeneity proposes that differences in specific resources and capabilities possessed by organizations can have the greatest impact on performance. Organizing approach indicates that firm level conditions that enhance effective exploitation of resources and capabilities would be more important in generating sustainable competitive advantage. Barney $(1991,2007)$ argued that attributes of advantage creating resources such as value, rareness, inimitability and non substitutability can be used to explain organizations performance.

From the dynamic capability school of thought, resources strengths need to be improved continually to sustain competition; this is to avoid instances where organizational routines could become core rigidities in the ever changing business environment (Grant,2005). Organizations that stay ahead of the pack must be able to identify specific resources that are relevant to strategic objectives, acquire or develop and effectively utilize them to meet the needs of the customers better than their rival.

Most RBT empirical literature observe that though both tangible and intangible resources contribute and are important for firm performance, it is the intangible resource that could be the main reason for sustained competitive advantage because competitors cannot easily replicate their use (Lui et al, 2010). Newbert (2007) observes that in most RBT studies, the level of empirical support for the theory varies considerably with the independent variable. Where independent variable is operationalized as a specific resource, empirical support is found in only $37 \%$ of tests done as opposed to where independent variable is operationalzed as value in which empirical support is found in all.

According to Newbert (2007), four methodological approaches grounded on RBT are used to test the relationship between independent and dependent variables. These approaches are the resource heterogeneity, the organizing level, the conceptual level and the dynamic capability. Scholars employing resource heterogeneity approach argue on theoretical grounds that a given resource, capability, or competence is valuable, rare, inimitable, and/or non- substitutable, quantify the amount of it possessed by a firm, and correlate this amount to some measure of performance. Organizing approach seek to identify those firm level conditions that enable the effective exploitation of the resources and capabilities under examination. They then test the effect of the interaction between a firm's resource and its organizing context (independent variable) on its performance (dependent variable).

The conceptual-level approach seeks to test whether the attributes prescribed by Barney (2007) as essential for a resource to effectively contribute to a firm's advantage are indeed significant predictors to this end. The proposition is that a firm's performance is a function of how well managers build their firms around resources that are valuable, rare, inimitable, and lack substitutes and then proceed to test for example the effect of a given isolating mechanism (a firm's competencies) on its performance. The dynamic capability approach tests the degree to which specific resource-level processes improve a firm's competitive position by operationalizing the independent variable as the interaction of a specific resource and a specific dynamic capability and testing its relationship with some measure of performance. Majority of studies employ only one of the approaches (Newbert, 2007).

\section{Methodology}

The study was carried out through a descriptive cross-sectional survey. According to Kombo and Tromp ( 2006), this design presents facts as they exist and would allow for correlation to enable the researcher assess the degree of relationship that exist between variables of study.

The resource heterogeneity approach (Newbert, 2007), an RBT research approach adopted from literature review, 
was the methodology of choice since the study sought to test the relationship between specific resource quantity possessed by county health services and performance using correlation and regression techniques. The population of the study was the 47 county health services departments of the 47 county governments in Kenya as created by the constitution of Kenya (2010). All the 47 counties were included in the study, hence a census study was carried out due to the small population size.

The study used secondary data from the results of exploratory research earlier conducted using ministry of health records (SARAM and Kenya health at a glance, 2013) in relation to tangible resources and performance of county health services. Each of the 47 counties had exploratory research summary findings on the quantity of current tangible resources and average county performance. Tangible resource information collected includes the levels of health facilities in terms of categories and capacities, equipment capacities in various service areas, transport capacities and human resource capacities for key health personnel. Information on performance collected included performance indicator achievements in areas of fully immunized child, TB completion, preventive ARV for HIV pregnant mothers, skilled deliveries, family planning coverage, and mortality in facilities, fresh still births, ante-natal attendance, latrine coverage, outpatient utilization, TB cure rate and maternal audits.

Both descriptive and inferential statistics were used to analyze the data. The descriptive statistics used were frequencies, percentages, mean scores and standard deviation. Inferential statistics involved both multivariate and hierarchical regression analysis. The regression model took the form of: $Y=a+b_{1} x_{1}+b_{2} x_{2} \ldots \ldots . b_{1} x_{11}$, where $\mathrm{Y}$ represented various performance indicator achievements (dependent variable), $\mathrm{x}$ represented tangible resources (independent variable), a represented constant and $\mathbf{b}$ the coefficients of various resources. The regression was done at $95 \%$ confidence level $(\mathrm{p}=0.05)$. The regression outputs used to interpret the findings include the multiple $\mathrm{r}, \mathrm{r}^{2}$, f-ratio, the $\mathrm{t}$-values and beta coefficients, and the sig. level values.

\section{Findings}

\section{Tangible Resources at County Health Services}

Tangible resources owned by the county health services were classified as physical infrastructure, equipments, transport, human resources and financial resources. Table 1 summarizes the nature of resources and quantification units.

Table1: Tangible Resource at County Health Service

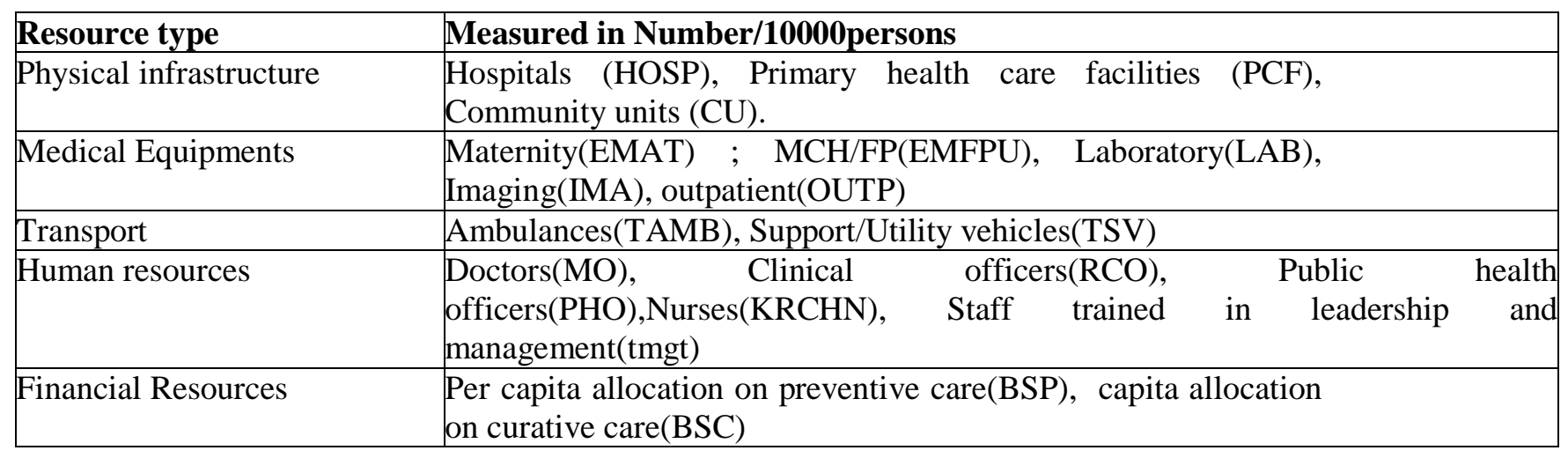

The resources disparities across counties are shown in the Table.2. The budget allocations are the most skewed with allocation for preventive services being the most followed by allocation for curative services. Medical personnel resources appear to be more equitably allocated compared to other resources with the doctors, public health officers clinical officers and nurses all recording standard deviations of less than 0.8. Generally there is significant resource heterogeneity across the counties and also across resource type. 
Table 2: Tangible Resources Disparities across Counties

\begin{tabular}{|l|l|l|l|l|l|}
\hline & $\mathrm{N}$ & Minimum & Maximum & Mean & Std. Deviation \\
\hline Mo & 47 & .04 & 2.85 & .5483 & .56405 \\
\hline Tmgt & 47 & 0.00 & 5.90 & 1.6511 & 1.78872 \\
\hline Rco & 47 & .09 & 4.72 & 1.2113 & .79692 \\
\hline Krchn & 47 & 1.30 & 11.52 & 3.6189 & 2.19174 \\
\hline Pho & 47 & .06 & 1.26 & .3774 & .29276 \\
\hline Hosp & 47 & 0.00 & 1.87 & .2466 & .39631 \\
\hline Pcf & 47 & 1.00 & 5.00 & 1.7234 & .82626 \\
\hline Cu & 47 & 0.00 & 1.67 & .4483 & 38304 \\
\hline Emat & 47 & 6.00 & 32.00 & 18.9574 & 6.89347 \\
\hline Emcfpu & 47 & 13.00 & 42.00 & 29.3617 & 7.55394 \\
\hline Lab & 47 & 1.00 & 17.00 & 5.5957 & 3.43042 \\
\hline Ima & 47 & 6.00 & 64.00 & 33.7021 & 13.13461 \\
\hline Outp & 47 & 8.00 & 70.00 & 29.2340 & 13.21431 \\
\hline Tamb & 47 & 0.00 & .50 & .1340 & 10483 \\
\hline Tsv & 47 & 0.00 & 1.30 & .3128 & .24901 \\
\hline Bsp & 47 & 256.00 & 1456.00 & 730.1915 & 245.77717 \\
\hline Bsc & 47 & 132.00 & 1212.00 & 438.5745 & 233.51005 \\
\hline Valid N (listwise) & 47 & & & & \\
\hline
\end{tabular}

\section{Performance Measurement of County Health Services}

The county health services performance were measured using health indicators that meet the various health objectives as per Kenya Health Sector Policy and Strategy Document. Table 3 summarizes the health performance measurements.

\section{Table 3: Performance Measure of County Health Services}

\section{Performance indicator}

$\%$ Fully immunized children

\% TB patients completing treatment

$\%$ HIV pregnant mothers on ARVS

$\%$ of deliveries conducted by skilled personnel

$\%$ of women of reproductive age receiving family planning

Facility based maternal mortality per 100,000 live births

$\%$ of pregnant women attending 4 ANC

$\%$ of households with latrines

Per capita outpatient Utilization rate

TB Cure rate

Maternal audits
Health objective

Eliminate non communicable diseases

Eliminate non communicable diseases

Eliminate non communicable diseases

Provide essential service

Provide essential services

Provide essential services

Provide essential services

Collaboration with stakeholders

Improved access

Improved quality

Table 4 presents the analysis of performances of 47 counties health departments against the national averages for the performance indicators used in this study.

Several counties performed poorly in maternal death audits, on putting HIV positive pregnant mothers on antiretroviral drugs and in the deliveries conducted by skilled personnel. Only in 5 out of 11 performance areas did more than half of the counties record above average performance. 
Table 4: Performance of Counties Health Departments against the National Averages for the Performance Indicators

\begin{tabular}{|l|l|l|}
\hline Performance Indicator & \%> average & \% < average \\
\hline Maternal deaths Audit madr & 11 & 89 \\
\hline TB Cure rate tbcr & 62 & 38 \\
\hline Per Capita Outpatient Utilization pcou & 49 & 51 \\
\hline Households with Latrines hswt & 34 & 66 \\
\hline Pregnant Women (4ANC Visits) pwanc & 51 & 49 \\
\hline Facility based Maternal mortality fbmm & 51 & 49 \\
\hline Women on Family Planning wrfp & 49 & 51 \\
\hline Deliveries conducted with Skilled personnel dcsa & 30 & 70 \\
\hline HIV Pregnant mothers on ARVs hivpm & 28 & 72 \\
\hline TB Patients tbp & 57 & 43 \\
\hline Fully Immunized children( fic) & 55 & 45 \\
\hline
\end{tabular}

There are significant performance differences across counties in almost all the performance indicators. High disparities were noted in households with latrines; facility based maternal mortality and maternal audits and deaths. These disparities are demonstrated by high standard deviation as shown in Table 5.

Table 5: Performance Indicators Disparities across Counties

\begin{tabular}{|l|l|l|l|l|l|}
\hline & N & Minimum & Maximum & Mean & Std. Dev. \\
\hline Fic & 47 & 41.90 & 103.60 & 74.9638 & 14.50788 \\
\hline Tbp & 47 & 72.00 & 95.00 & 87.6383 & 4.48876 \\
\hline Hivpm & 47 & 40.00 & 138.50 & 83.8000 & 21.93018 \\
\hline Dcsa & 47 & 15.80 & 96.20 & 38.5021 & 18.66475 \\
\hline Wrfp & 47 & 3.00 & 97.70 & 39.7957 & 19.43377 \\
\hline Fbmm & 47 & 0.00 & 436.00 & 171.3021 & 100.37170 \\
\hline Pwanc & 47 & 14.00 & 94.10 & 46.6468 & 13.92743 \\
\hline Hswt & 47 & 0.00 & 1791.00 & 123.4426 & 276.50992 \\
\hline Pcou & 47 & .20 & 3.50 & 1.0447 & .50726 \\
\hline Tbcr & 47 & 38.00 & 98.00 & 80.8872 & 9.08665 \\
\hline Madr & 47 & 0.00 & 460.00 & 45.8596 & 90.11654 \\
\hline Valid N (listwise) & 47 & & & & \\
\hline
\end{tabular}

\section{Tangible Resources and Performance of County Health Services}

The relationship between tangible resources and performance was established using multiple and hierarchical regression analyses. First, the independent effects of the tangible resources on each indicator of performance were determined. These were then followed by the combined effect of the tangible resources on each indicator of performance. The results of the independent effects of the tangible resources on each indicator of performance are first presented.

\section{Tangible Resources and Fully Immunized Child}

Tangible resources were regressed on the fully immunized child to ascertain their influence. The results in Table 6 provide a detailed summary of each resource contribution to performance. The most important finding is the importance (significance $=0.009$ ) of maternal and child equipments to the model. However, 1 per 10000 persons ( 1 unit) maternal child equipment can potentially only realize 0.721 change in performance in fully immunized child. The more available these equipments are in the counties the better the performance. Investing in maternal and child equipments (emcfpu) increases access to child immunization more than investing in any other resource that is evidently not contributing to this model due to the high $\mathrm{p}$ values. 
Table 6: Independent Effect of Tangible Resources of Fully Immunized Child

\begin{tabular}{|l|l|l|l|l|l|}
\hline \multirow{2}{*}{ Tangible Resources } & \multicolumn{2}{l|}{$\begin{array}{l}\text { Unstandardized } \\
\text { Coefficients }\end{array}$} & $\begin{array}{l}\text { Standardized } \\
\text { Coefficients } \\
\text { Beta }\end{array}$ & t-Value & Sig. \\
\cline { 2 - 6 } & $\mathbf{B}$ & Std. Error & & \\
\hline (Constant) & 38.983 & 14.625 & & 2.665 & .012 \\
\hline Mo & 13.684 & 9.662 & .532 & 1.416 & .167 \\
\hline Tmgt & -.618 & 1.527 & -.076 & -.405 & .689 \\
\hline Rco & -6.798 & 7.021 & -.373 & -.968 & .341 \\
\hline krchn & -2.414 & 2.467 & -.365 & -.979 & .336 \\
\hline Pho & 10.640 & 11.787 & .215 & .903 & .374 \\
\hline Hosp & -4.476 & 8.449 & -.122 & -.530 & .600 \\
\hline Pcf & 4.097 & 4.303 & .233 & .952 & .349 \\
\hline Cu & 3.182 & 8.670 & .084 & .367 & .716 \\
\hline Emat & -.396 & .614 & -.188 & -.644 & .524 \\
\hline emcfpu & 1.385 & .493 & .721 & 2.808 & .009 \\
\hline Lab & .402 & .966 & .095 & .417 & .680 \\
\hline Ima & .066 & .216 & .060 & .304 & .763 \\
\hline Outp & -.157 & .220 & -.143 & -.716 & .479 \\
\hline Tamb & 36.368 & 32.091 & .263 & 1.133 & .266 \\
\hline Tsv & -2.810 & 13.689 & -.048 & -.205 & .839 \\
\hline Bsp & .007 & .015 & .126 & .500 & .621 \\
\hline Bsc & -.017 & .017 & -.270 & -.964 & .343 \\
\hline
\end{tabular}

Tangible Resources and TB Patients completing treatments

Tangible resources were regressed on the TB patients completing treatments to ascertain their influence. The results in Table 7 indicate that all the tangible resources that were considered for the study had statistically not significant independent effect on TB patients completing treatments (low t-values, $\mathrm{p}<0.05$ ).

Table 7: Tangible Resources and TB Patients completing treatments

\begin{tabular}{|l|l|l|l|l|l|}
\hline \multirow{2}{*}{ Tangible Resources } & \multicolumn{2}{|c|}{$\begin{array}{c}\text { Unstandardized } \\
\text { Coefficients }\end{array}$} & \multicolumn{1}{c|}{$\begin{array}{c}\text { Standardized } \\
\text { Coefficients } \\
\text { Beta }\end{array}$} & t-Value & Sig. \\
\cline { 2 - 3 } & \multicolumn{1}{|c|}{ B } & \multicolumn{1}{|c|}{ Std. Error } & & \\
\hline (Constant) & 89.595 & 4.882 & & 18.352 & .000 \\
\hline Mo & -1.802 & 3.225 & -.226 & -.559 & .581 \\
\hline Tmgt & .244 & .510 & .097 & .479 & .635 \\
\hline Rco & -2.297 & 2.344 & -.408 & -.980 & .335 \\
\hline krchn & 1.495 & .824 & .730 & 1.815 & .080 \\
\hline Pho & -3.051 & 3.935 & -.199 & -.776 & .444 \\
\hline Hosp & -.631 & 2.820 & -.056 & -.224 & .824 \\
\hline Pcf & -.765 & 1.436 & -.141 & -.533 & .598 \\
\hline Cu & 1.610 & 2.894 & .137 & .556 & .582 \\
\hline Emat & .109 & .205 & .167 & .531 & .600 \\
\hline emcfpu & -.119 & .165 & -.201 & -.724 & .475 \\
\hline Lab & -.179 & .323 & -.137 & -.554 & .584 \\
\hline Ima & .142 & .072 & .415 & 1.964 & .059 \\
\hline Outp & -.066 & .073 & -.196 & -.907 & .372 \\
\hline Tamb & -1.262 & 10.712 & -.029 & -.118 & .907 \\
\hline Tsv & -5.174 & .005 & -.287 & -1.132 & .267 \\
\hline Bsp & -.002 & .006 &. .102 & -.377 & .709 \\
\hline Bsc & .002 & .078 & .258 & .798 \\
\hline
\end{tabular}

Tangible Resources and \% of HIV Pregnant Mothers Receiving ARVs 
Tangible resources were regressed on the percentage of HIV pregnant mothers receiving ARVs to ascertain their influence. Table 8 provides a detailed summary of each resource contribution to this indicator of performance. The results indicate that it only the maternal and child equipments that had statistically independent effect on the percentage of HIV pregnant mothers receiving ARVs ( $\mathrm{p}<0.05)$. However, 1 per 10000 persons ( 1 unit) maternal child equipment can potentially realize 1.61 change in the performance indicator.

The more available these equipments are in the counties the better the performance. Investing in maternal and child equipments (emcfpu) increases access to ARV for HIV pregnant mothers and preventing maternal to child transmission.

Table 8: Tangible Resources and \% of HIV Pregnant Mothers Receiving ARVs

\begin{tabular}{|l|l|l|l|l|l|}
\hline \multirow{2}{*}{ Tangible Resources } & \multicolumn{2}{l|}{$\begin{array}{l}\text { Unstandardized } \\
\text { Coefficients }\end{array}$} & $\begin{array}{l}\text { Standardized } \\
\text { Coefficients } \\
\text { Beta }\end{array}$ & t-Value & Sig. \\
\cline { 2 - 6 } & B & Std. Error & & \\
\hline (Constant) & 22.641 & 19.075 & & 1.187 & .245 \\
\hline Mo & .428 & 12.601 & .011 & .034 & .973 \\
\hline Tmgt & 3.654 & 1.992 & .298 & 1.835 & .077 \\
\hline Rco & -7.082 & 9.157 & -.257 & -.773 & .446 \\
\hline krchn & -3.413 & 3.218 & -.341 & -1.061 & .298 \\
\hline Pho & 10.467 & 15.373 & .140 & .681 & .501 \\
\hline Hosp & -9.733 & 11.020 & -.176 & -.883 & .384 \\
\hline Pcf & 6.597 & 5.612 & .249 & 1.176 & .249 \\
\hline Cu & 5.475 & 11.307 & .096 & .484 & .632 \\
\hline Emat & -.593 & .801 & -.186 & -.740 & .465 \\
\hline emcfpu & 1.610 & .643 & .555 & 2.504 & .018 \\
\hline Lab & 1.990 & 1.260 & .311 & 1.579 & .125 \\
\hline Ima & .248 & .282 & .148 & .878 & .387 \\
\hline Outp & -.023 & .287 & -.014 & -.080 & .937 \\
\hline Tamb & 40.962 & 41.854 & .196 & .979 & .336 \\
\hline Tsv & -4.554 & 17.854 & -.052 & -.255 & .800 \\
\hline Bsp & -.012 & .019 & -.136 & -.628 & .535 \\
\hline Bsc & .024 & .023 & .253 & 1.043 & .306 \\
\hline
\end{tabular}

Tangible Resources and Deliveries Conducted by Skilled Personnel

Tangible resources were regressed on the percentage deliveries conducted by skilled personnel to ascertain their influence. The results presented in Table 9 show that maternal and child equipments have statistically significant independent effect $(\mathrm{p}<0.05)$. However, 1 per 10000 persons ( 1 unit) maternal child equipment can potentially realize $1.3 \%$ change in performance indicator. The more available these equipments are in the counties the better the performance. Investing in maternal and child equipments (emcfpu) increases access skilled deliveries. 
Table 9: Tangible Resources and Deliveries Conducted by Skilled Personnel

\begin{tabular}{|l|l|l|l|l|l|}
\hline \multirow{2}{*}{ Tangible Resources } & \multicolumn{2}{l}{$\begin{array}{l}\text { Unstandardized } \\
\text { Coefficients }\end{array}$} & $\begin{array}{l}\text { Standardized } \\
\text { Coefficients } \\
\text { Beta }\end{array}$ & t-Value & Sig. \\
\cline { 2 - 6 } & B & Std. Error & & \\
\hline (Constant) & 8.802 & 17.847 & & .493 & .626 \\
\hline Mo & 7.471 & 11.791 & .226 & .634 & .531 \\
\hline Tmgt & -2.884 & 1.864 & -.276 & -1.548 & .133 \\
\hline Rco & 3.857 & 8.568 & .165 & .450 & .656 \\
\hline krchn & -2.057 & 3.011 & -.242 & -.683 & .500 \\
\hline Pho & -10.384 & 14.384 & -.163 & -.722 & .476 \\
\hline Hosp & 5.498 & 10.311 & .117 & .533 & .598 \\
\hline Pcf & 9.671 & 5.251 & .428 & 1.842 & .076 \\
\hline Cu & -10.759 & 10.580 & -.221 & -1.017 & .318 \\
\hline Emat & .192 & .749 & .071 & .256 & .800 \\
\hline emcfpu & 1.304 & .602 & .528 & 2.167 & .039 \\
\hline Lab & .734 & 1.179 & .135 & .622 & .539 \\
\hline Ima & -.211 & .264 & -.148 & -.798 & .432 \\
\hline Outp & -.031 & .268 & -.022 & -.114 & .910 \\
\hline Tamb & 2.470 & 39.161 & .014 & .063 & .950 \\
\hline Tsv & -23.830 & 16.705 & -.318 & -1.427 & .164 \\
\hline Bsp & .012 & .018 & .159 & .666 & .511 \\
\hline Bsc & -.036 & .021 & -.453 & -1.703 & .099 \\
\hline
\end{tabular}

Tangible Resources and Women of Reproductive Age Receiving Family Planning

The results of the independent effect of tangible resources on the women of reproductive age receiving family planning show that maternal and child equipments and primary care facilities have statistically significant effects on women of reproductive age receiving family planning $(\mathrm{p}<0.05)$. The results therefore indicate that an additional 1 per 10000 persons( 1 unit) maternal child equipment can potentially realize $1.624 \%$ change in performance indicator while one unit change in primary care units results in $14.37 \%$ change in access to family planning. The more available these resources are in the counties the better the performance indicator. These results are presented in Table 10.

Table 10: Tangible Resources and Women of Reproductive Age Receiving Family Planning

\begin{tabular}{|c|c|c|c|c|c|}
\hline \multirow[t]{2}{*}{ Tangible Resources } & \multicolumn{2}{|c|}{$\begin{array}{l}\text { Unstandardized } \\
\text { Coefficients }\end{array}$} & \multirow{2}{*}{$\begin{array}{c}\text { Standardized } \\
\text { Coefficients } \\
\text { Beta }\end{array}$} & \multirow[t]{2}{*}{ t-Value } & \multirow[t]{2}{*}{ Sig. } \\
\hline & B & Std. Error & & & \\
\hline (Constant) & $\begin{array}{l}-15.973 \\
\end{array}$ & 17.087 & & -.935 & .358 \\
\hline Mo & 16.317 & 1.288 & .474 & 1.445 & .159 \\
\hline Tmgt & -.807 & 1.784 & -.074 & -.452 & .655 \\
\hline Rco & -9.964 & $\beta .203$ & -.409 & -1.215 & .234 \\
\hline krchn & -1.855 & 2.882 & -.209 & -.644 & .525 \\
\hline Pho & 2.882 & 3.772 & .043 & .209 & .836 \\
\hline Hosp & -7.945 & 9.872 & -.162 & -.805 & .428 \\
\hline Pcf & 14.370 & 5.027 & .611 & 2.859 & .008 \\
\hline $\mathrm{Cu}$ & 3.492 & 10.129 & .069 & .345 & .733 \\
\hline Emat & -.021 & 717 & -.007 & -.029 & .977 \\
\hline emcfpu & 1.624 & 576 & .631 & 2.819 & .009 \\
\hline $\mathrm{Lab}$ & .076 & 1.129 & .013 & .068 & .946 \\
\hline Ima & .097 & 253 & .066 & .384 & .703 \\
\hline Outp & -.079 & 257 & -.054 & -.309 & .759 \\
\hline Tamb & 20.028 & 37.494 & .108 & .534 & .597 \\
\hline Tsv & -14.645 & 5.994 & -.188 & -.916 & .367 \\
\hline Bsp & -.001 & 017 & -.016 & -.071 & .944 \\
\hline Bsc & -.010 & 020 & -.121 & -.493 & .625 \\
\hline
\end{tabular}




\section{Tangible Resources and Facility Based Maternal Mortality}

The results on the independent influence of tangible resources on facility based maternal mortality show a statistically significant independent effect for support/utility vehicles and clinical officers $(\mathrm{p}<0.05)$. This means that for each additional 1:10000 clinical officer there is significant change in facility based maternal deaths. Similarly, for each unit change in utility vehicle to population ratio there may be $205 \%$ reduction in the deaths, when the other variables are held constant. The results are presented in Table 11.

Table 11: Tangible Resources and Facility Based Maternal Mortality

\begin{tabular}{|c|c|c|c|c|c|}
\hline \multirow[t]{2}{*}{ Tangible Resources } & \multicolumn{2}{|c|}{$\begin{array}{l}\text { Unstandardized } \\
\text { Coefficients }\end{array}$} & \multirow{2}{*}{$\begin{array}{l}\text { Standardized } \\
\text { Coefficients } \\
\text { Beta }\end{array}$} & \multirow[t]{2}{*}{ t-Value } & \multirow[t]{2}{*}{ Sig. } \\
\hline & B & Std. Error & & & \\
\hline (Constant) & 313.469 & 88.853 & & 3.528 & .001 \\
\hline Mo & -2.517 & 58.699 & -.014 & -.043 & .966 \\
\hline Tmgt & -9.181 & 9.278 & -.164 & -.990 & .331 \\
\hline Rco & 117.025 & 42.655 & .929 & 2.744 & .010 \\
\hline krchn & -19.957 & 14.988 & -.436 & -1.331 & .193 \\
\hline Pho & -111.261 & 71.611 & -.325 & -1.554 & .131 \\
\hline Hosp & -41.682 & 51.333 & -.165 & -.812 & .423 \\
\hline Pcf & -50.539 & 26.140 & -.416 & -1.933 & .063 \\
\hline $\mathrm{Cu}$ & -48.809 & 52.672 & -.186 & -.927 & .362 \\
\hline Emat & -3.121 & 3.731 & -.214 & -.837 & .410 \\
\hline emcfpu & -3.560 & 2.996 & -.268 & -1.188 & .244 \\
\hline Lab & 2.024 & 5.871 & .069 & .345 & .733 \\
\hline Ima & .692 & 1.314 & .091 & .527 & .602 \\
\hline Outp & .356 & 1.335 & .047 & .267 & .792 \\
\hline Tamb & -241.757 & 194.964 & -.253 & -1.240 & .225 \\
\hline Tsv & 205.845 & 83.165 & .511 & 2.475 & .019 \\
\hline Bsp & .159 & .090 & .389 & 1.760 & .089 \\
\hline Bsc & -.144 & .106 & -.335 & -1.361 & .184 \\
\hline
\end{tabular}

Tangible Resources and Pregnant Women Attending 4 ANC

The results on the independent effect of tangible resources on pregnant women attending 4 ANC show not statistically significant independent effect for all the tangible resources. This means that there are other factors that could be responsible significant changes in this indicator of performance. the results are presented in Table 12.

Table 12: Tangible Resources and Pregnant Women Attending 4 ANC

\begin{tabular}{|c|c|c|c|c|c|}
\hline \multirow[t]{2}{*}{ Tangible Resources } & \multicolumn{2}{|c|}{$\begin{array}{l}\text { Unstandardized } \\
\text { Coefficients }\end{array}$} & \multirow{2}{*}{$\begin{array}{l}\text { Standardized } \\
\text { Coefficients } \\
\text { Beta }\end{array}$} & \multirow[t]{2}{*}{ t-Value } & \multirow[t]{2}{*}{ Sig. } \\
\hline & B & Std. Error & & & \\
\hline (Constant) & 30.262 & 14.365 & & 2.107 & .044 \\
\hline Mo & 3.618 & 9.490 & .147 & .381 & .706 \\
\hline Tmgt & 1.000 & 1.500 & .128 & .667 & .510 \\
\hline Rco & -6.989 & 6.896 & -.400 & -1.013 & .319 \\
\hline krchn & .647 & 2.423 & .102 & .267 & .791 \\
\hline Pho & 9.779 & 11.578 & .206 & .845 & .405 \\
\hline Hosp & 7.418 & 8.299 & .211 & .894 & .379 \\
\hline Pcf & 2.899 & 4.226 & .172 & .686 & .498 \\
\hline $\mathrm{Cu}$ & .909 & 8.516 & .025 & .107 & .916 \\
\hline Emat & -.277 & .603 & -.137 & -.459 & .650 \\
\hline emcfpu & .626 & .484 & .340 & 1.293 & .206 \\
\hline Lab & .003 & .949 & .001 & .004 & .997 \\
\hline Ima & .115 & .212 & .109 & .543 & .592 \\
\hline Outp & -.416 & .216 & -.395 & -1.927 & .064 \\
\hline Tamb & 23.601 & 31.521 & .178 & .749 & .460 \\
\hline Tsv & -16.612 & 13.446 & -.297 & -1.235 & .227 \\
\hline Bsp & $3.172 \mathrm{E}-005$ & .015 & .001 & .002 & .998 \\
\hline Bsc & .012 & .017 & .194 & .674 & .506 \\
\hline
\end{tabular}




\section{Tangible Resources and Households with Latrines}

Tangible resources were regressed on the households with latrines to ascertain their influence. Primary care facilities was found to have statistically significant influence $(\mathrm{p}<0.05)$. This means that for each unit change in the ratio of primary health care facilities to 10000 persons there will be $174 \%$ increase in households with latrines. The results are presented in Table 13.

Table 13: Tangible Resources and Households with Latrines

\begin{tabular}{|c|c|c|c|c|c|}
\hline \multirow[t]{2}{*}{ Tangible Resources } & \multicolumn{2}{|c|}{$\begin{array}{l}\text { Unstandardized } \\
\text { Coefficients }\end{array}$} & \multirow{2}{*}{$\begin{array}{l}\text { Standardized } \\
\text { Coefficients } \\
\text { Beta }\end{array}$} & \multirow[t]{2}{*}{ t-Value } & \multirow[t]{2}{*}{ Sig. } \\
\hline & B & Std. Error & & & \\
\hline (Constant) & -200.564 & 246.342 & & -.814 & .422 \\
\hline Mo & -80.159 & 162.741 & -.164 & -.493 & .626 \\
\hline Tmgt & -42.398 & 25.722 & -.274 & -1.648 & .110 \\
\hline Rco & -66.243 & 118.260 & -.191 & -.560 & .580 \\
\hline krchn & 21.379 & 41.555 & .169 & .514 & .611 \\
\hline Pho & 49.420 & 198.538 & .052 & .249 & .805 \\
\hline Hosp & 4.264 & 142.319 & .006 & .030 & .976 \\
\hline Pcf & 174.034 & 72.473 & .520 & 2.401 & .023 \\
\hline $\mathrm{Cu}$ & 236.190 & 146.030 & .327 & 1.617 & .117 \\
\hline Emat & 20.678 & 10.343 & .516 & 1.999 & .055 \\
\hline emcfpu & .654 & 8.307 & .018 & .079 & .938 \\
\hline Lab & -12.087 & 16.276 & -.150 & -.743 & .464 \\
\hline Ima & -1.631 & 3.644 & -.077 & -.448 & .658 \\
\hline Outp & -2.858 & 3.700 & -.137 & -.772 & .446 \\
\hline Tamb & 395.499 & 540.529 & .150 & .732 & .470 \\
\hline Tsv & -127.160 & 230.572 & -.115 & -.551 & .586 \\
\hline Bsp & -.201 & .250 & -.179 & -.805 & .427 \\
\hline Bsc & -.128 & .294 & -.108 & -.434 & .667 \\
\hline
\end{tabular}

\section{Tangible Resources and Per Capita Outpatient Utilization}

Tangible resources were regressed on the percapita outpatient utilization to ascertain their influence. The results indicate that primary health care facilities had statistically significant independent effect on per capita outpatient utilization $(p<0.05)$. However, this contributes only 0.462 of the change in the of the performance indicator. These results are presented in Table 14.

Table 14: Tangible Resources and Per Capita Outpatient Utilization

\begin{tabular}{|c|c|c|c|c|c|}
\hline Tangible Resources & \multicolumn{2}{|c|}{$\begin{array}{c}\text { Unstandardized } \\
\text { Coefficients }\end{array}$} & $\begin{array}{c}\text { Standardized } \\
\text { Coefficients } \\
\text { Beta }\end{array}$ & t-Value & Sig \\
\hline (Constant) & .315 & .479 & & .657 & .516 \\
\hline Tmgt & -.053 & .050 & -.185 & -1.050 & .302 \\
\hline Rco & -.302 & .230 & -.474 & -1.312 & .200 \\
\hline krchn & -.139 & .081 & -.600 & -1.717 & .097 \\
\hline Pcf & .462 & .141 & .752 & 3.275 & .003 \\
\hline $\mathrm{Cu}$ & .233 & .284 & .176 & .822 & .418 \\
\hline Emat & -.032 & .020 & -.430 & -1.573 & .126 \\
\hline emcfpu & .043 & .016 & .644 & 2.675 & .012 \\
\hline $\mathrm{Lab}$ & .017 & .032 & .117 & .545 & .590 \\
\hline Bsp & $\begin{array}{l}1.065 \mathrm{E}- \\
005\end{array}$ & .000 & .005 & .022 & .983 \\
\hline Bsc & -.001 & .001 & -.277 & -1.055 & .300 \\
\hline
\end{tabular}




\section{Tangible Resources and TB Cure Rate}

The results on the independent effect of tangible resources on TB cure rate show statistically not significant influence as shown in Table $15(\mathrm{p}>0.05)$.

Table 15: Tangible Resources and TB Cure Rate

\begin{tabular}{|c|c|c|c|c|c|}
\hline \multirow[t]{2}{*}{ Tangible Resources } & \multicolumn{2}{|c|}{$\begin{array}{l}\text { Unstandardized } \\
\text { Coefficients }\end{array}$} & \multirow{2}{*}{$\begin{array}{l}\text { Standardized } \\
\text { Coefficients } \\
\text { Beta }\end{array}$} & \multirow[t]{2}{*}{ t-Value } & \multirow[t]{2}{*}{ Sig. } \\
\hline & B & Std. Error & & & \\
\hline (Constant) & 85.027 & 9.654 & & 8.808 & .000 \\
\hline Mo & -10.301 & 6.378 & -.639 & -1.615 & .117 \\
\hline Tmgt & -.091 & 1.008 & -.018 & -.090 & .929 \\
\hline Rco & -1.698 & 4.634 & -.149 & -.366 & .717 \\
\hline krchn & 1.759 & 1.628 & .424 & 1.080 & .289 \\
\hline Pho & -8.828 & 7.780 & -.284 & -1.135 & .266 \\
\hline Hosp & 7.213 & 5.577 & .315 & 1.293 & .206 \\
\hline Pcf & 3.823 & 2.840 & .348 & 1.346 & .189 \\
\hline $\mathrm{Cu}$ & -3.188 & 5.723 & -.134 & -.557 & .582 \\
\hline Emat & .100 & .405 & .076 & .247 & .807 \\
\hline emcfpu & -.189 & .326 & -.157 & -.579 & .567 \\
\hline Lab & .238 & .638 & .090 & .374 & .711 \\
\hline Ima & .201 & .143 & .291 & 1.408 & .170 \\
\hline Outp & -.172 & .145 & -.250 & -1.186 & .245 \\
\hline Tamb & 2.651 & 21.182 & .031 & .125 & .901 \\
\hline Tsv & -3.528 & 9.036 & -.097 & -.390 & .699 \\
\hline Bsp & -.008 & .010 & -.227 & -.858 & .398 \\
\hline Bsc & .003 & .012 & .070 & .236 & .815 \\
\hline
\end{tabular}

\section{Tangible Resources and Maternal audits/Death audits}

Tangible resources were regressed on maternal audits to ascertain their independent influence. The results show that community units and laboratory had statistically independent effect on maternal audits/death audits $(\mathrm{p}<0.05)$ This means that for each unit change in laboratory equipments there can be $15 \%$ change of audits. Similarly one unit change in community units can generate $153 \%$ change in maternal audits.

Table 16: Tangible Resources and Maternal audits/Death audits

\begin{tabular}{|l|l|l|l|l|l|}
\hline \multirow{2}{*}{ Tangible Resources } & $\begin{array}{l}\text { Unstandardized } \\
\text { Coefficients }\end{array}$ & $\begin{array}{l}\text { Standardized } \\
\text { Coefficients } \\
\text { Beta }\end{array}$ & S-Value & Sig. \\
\cline { 2 - 6 } & B & Std. Error & & & \\
\hline (Constant) & 62.182 & 94.562 & & .658 & .516 \\
\hline Mo & -90.553 & 62.471 & -.567 & -1.450 & .158 \\
\hline Tmgt & -7.159 & 9.874 & -.142 & -.725 & .474 \\
\hline Rco & -2.567 & 45.396 & -.023 & -.057 & .955 \\
\hline krchn & 13.874 & 15.951 & .337 & .870 & .392 \\
\hline Pho & -5.184 & 76.212 & -.017 & -.068 & .946 \\
\hline Hosp & 81.556 & 54.631 & .359 & 1.493 & .146 \\
\hline Pcf & 31.872 & 27.820 & .292 & 1.146 & .261 \\
\hline Cu & -153.449 & 56.056 & -.652 & -2.737 & .010 \\
\hline Emat & 2.722 & 3.970 & .208 & .686 & .498 \\
\hline emcfpu & -2.702 & 3.189 & -.226 & -.847 & .404 \\
\hline Lab & 15.730 & 6.248 & .599 & 2.518 & .018 \\
\hline Ima & -1.218 & 1.399 & -.178 & -.871 & .391 \\
\hline Outp & -.506 & 1.420 & -.074 & -.356 & .724 \\
\hline Tamb & -254.920 & 207.490 & -.297 & -1.229 & .229 \\
\hline Tsv & -35.152 & 88.509 & -.097 & -.397 & .694 \\
\hline Bsp & .062 & .096 & .170 & .648 & .522 \\
\hline Bsc & -.025 & .113 & -.065 & -.221 & .826 \\
\hline
\end{tabular}




\section{Combined Effect of Tangible Resources on the Various Indicators of performance}

The preliminary results presented have provided a glimpse of the independent effects of tangible resources on each indicator of performance. This section focuses on ascertaining the combined of the tangible resources on each of the indicators of performance. Through hierarchical regression analysis, the resultant multiple correlation coefficients ( $r$ ) determine the degree of the relationships between tangible resources and each performance indicator. Regression analysis provided the model equation for predicting the performance from a given set of resource inputs. Each performance indicator was regressed on all tangible resources and the coefficients of determination $\left(\mathrm{r}^{2}\right)$ values were used to provide explanation for variations in performance as explained by the tangible resource inputs. The resultant F-ratios predicted the statistical significance of the models at the set level of significance $(95 \% ; \mathrm{p}=0.05)$. The summary of the model results are presented in Table 17.

Table 17: Combined Effect of Tangible Resources on the Various Indicators of performance

\begin{tabular}{|c|c|c|c|c|}
\hline Model & $\begin{array}{l}\text { Multiple } \\
\text { R }\end{array}$ & $\mathrm{R}^{2}$ & F-Ratio & Sig. \\
\hline Fully Immunized Child = f(Tangible Resources) & 0.636 & 0.404 & 1.157 & 0.354 \\
\hline TB Patients completing treatments $=\mathbf{f}($ Tangible Resources) & 0.554 & 0.306 & 0.754 & 0.726 \\
\hline $\begin{array}{l}\% \text { of HIV Pregnant Mothers Receiving } \mathrm{ARV}_{\mathrm{S}}=\mathbf{f}(\text { Tangible } \\
\text { Resources) }\end{array}$ & 0.746 & 0.556 & 2.140 & 0.035 \\
\hline $\begin{array}{l}\text { Deliveries Conducted by Skilled Personnel= f(Tangible } \\
\text { Resources) }\end{array}$ & 0.681 & 0.464 & 1.476 & 0.173 \\
\hline $\begin{array}{l}\text { Women of Reproductive Age Receiving } \\
\text { Family Planning=f(Tangible Resources) }\end{array}$ & 0.739 & 0.547 & 2.057 & 0.042 \\
\hline Facility Based Maternal Mortality= f(Tangible Resources) & 0.735 & 0.541 & 2.007 & 0.048 \\
\hline Pregnant Women Attending 4 ANC $=\mathbf{f}($ Tangible Resources $)$ & 0.613 & 0.376 & 1.029 & 0.459 \\
\hline Households with Latrines $=$ f(Tangible Resources) & 0.731 & 0.535 & 1.960 & 0.054 \\
\hline Per Capita Outpatient Utilization $=\mathbf{f}$ (Tangible Resources) & 0.691 & 0.477 & 1.556 & 0.143 \\
\hline TB Cure Rate $=\mathbf{f}($ Tangible Resources $)$ & 0.582 & 0.338 & 0.872 & 0.608 \\
\hline Maternal audits/Death audits $=\mathbf{f}$ (Tangible Resources) & 0.595 & 0.354 & 0.936 & 0.545 \\
\hline \multicolumn{5}{|c|}{$\begin{array}{l}\text { Tangible Resources: Hospitals (HOSP), Primary health care facilities (PCF), Community units } \\
\text { (CU). Maternity(EMAT); MCH/FP(EMFPU), Laboratory(LAB), Imaging(IMA), outpatient(OUTP), } \\
\text { Ambulances(TAMB), Support/Utility vehicles(TSV), Doctors(MO), Clinical officers(RCO), Public } \\
\text { health officers(PHO),Nurses(KRCHN), Staff trained in leadership and management(tmgt), Per capita } \\
\text { allocation on preventive care(BSP), capita allocation on curative care(BSC) }\end{array}$} \\
\hline
\end{tabular}

The results in Table 16 indicate that for the combined effect of tangible resources on the various indicators of performance, statistically significant results were reported for women reproductive age receiving family planning, facility based maternal mortality and households with latrines (high F-ratios, high absolute t-values and $\mathrm{p}<0.05)$. The combined effect of other resources on the various indicators of performance reported statistically not significant results (low F-ratios, low absolute t-values and p>0.05).

\section{Discussion}

It is noted from the findings that there exists inequitable distribution of tangible health resources across counties in Kenya. The notable disparities are found in the financial resources and equipments. This inequality may be responsible for the county performance differentials.

It is not unusual for organizations to have differences in resource levels in terms of quantity and quality and this has been observed in the literature as a cornerstone of the resource based theory (RBV). The resource heterogeneity factor or firm level difference is one of the views used to explain performance differences among firms in the same industry. This study is in agreement with the three central tenets of the RBT logic. First, it confirms that resource heterogeneity can be used to explain performance differentials. Secondly this study found that only specific resources were responsible for superior performance. It was these particular strategic resources that set counties apart in terms of performance. Thirdly the RBT framework was successfully used to identify resources most useful to performance. For social service organizations such as health, resource deployment should not be left to market forces or political expediency. Indeed in the WHO framework equity is recognized as a vehicle to achieving the health goals (Maynard \& Bloor, 1995). 
The findings also revealed performance differences among counties. This is consistent with the resource disparities observed earlier and is a pointer that resources do influence performance. Wide performance disparities were mainly observed in TB cure rate, households with latrines, facility based maternal mortality and maternal audits all of which draw significant part of their financial resources from preventive services allocation.

Regression model, although useful, should be interpreted with caution and used more as a guide. In social science performance determinants cannot be held constant and there are many variables at play that influence performance in un-predictive pattern. It has been observed however that tangible resources can have influence over performance. The influence may be positive or negative. However, it is the specific resources which explained superior performance.

The findings corroborate the empirical findings by researchers. Carmeli et al (2004) on their study involving industrial enterprises in Israel when investigating the influence of organizational resources on variations in firm performance found that intangible resources and capabilities were more critical to firm performance than structural resources. This may be a possible explanation of low correlations on hospitals and the health indicators. Bellaterra (2006) on evaluating efficiency in textile and clothing industry in the framework of resource based view (RBV) found that tangible assets are correlated with performance of firms in Poland and Spain. Newbert (2007) on reviewing RBT approaches observed that 50\% of researches that use tangible resources and performance as constructs show strong positive correlations between the two variables.

\section{Implications for Policy and Practice}

This study recommends a relook at how tangible resources are distributed across counties with a view to improvements on the resource allocation policy that eliminates the evident resource disparities. The constitution of Kenya strongly supports the principle of equity in resource allocation.

For the practice, facility health managers, need to acquire and deploy the respective identified tangible resources in terms of types and levels that are currently critical for a given performance area. They also need to monitor resource trends in order to identify those resources that can maximize performance. These resources may be identified using the framework provided by this study. It is confirmed by this study that the levels of specific resource and types are important to performance.

The fact that there is still a large percentage that fails to explain performance in terms of the tangible resources listed in this study, it would be interesting to look at the influence of intangible resources on the performance of county health services. This is because tangible resources cannot on their own produce performance. The counties need to support such a research so that investments in health are based on evidence.

\section{Limitations and Suggestions for Further Study}

The first limitation of the study was the use of several measures of performance which did not measure overall efficiency for comparative purposes. Technical efficiency which has been used by researchers to measure efficiency of health performance systems should be used to provide a composite index for health attainment of goals. The composite index is a weighted average of the component goals. First, county attainment on all indicators (i.e., health inequality, responsiveness-level, responsiveness-distribution, and fair- financing) are rescaled restricting them to the $[0,1]$ interval. Then weights were used to construct the overall composite measure: $25 \%$ for health (DALE), $25 \%$ for health inequality, $12.5 \%$ for the level of responsiveness, $12.5 \%$ for the distribution of responsiveness, and $25 \%$ for fairness in financing. This was beyond the scope of this study.

Secondly, the accuracy of secondary data used in the study could not be guaranteed. Some of the interpretations must be taken with caution as the quality of the data determines the reliability of the outputs. Thirdly, resources had been evaluated singly yet there could be complimentarity or co-specialization of resources. This was beyond the scope of this study but can affect the findings.

Still this research had used resource heterogeneity methodological approach. A combination of organizing level, the conceptual, and the dynamic capability methodologies is recommended in RBT researches that involve testing the relationship between resources and performance (Newbert, 2007). The study had also used linear regression models in the analysis with its inherent assumptions which may not hold true in the circumstances. Other advanced statistical models were not tested for best fit to the data. 
There are several elements not undertaken by the model presented in this study. A very important element missing in the model and emphasized by resource -based view are the firms' capabilities and their influence on performance. Moreover, RBV framework do not explain the process through which some firms reach competitive advantage in situations of change, attributed to dynamic environments. Strategy scholars tend to modify RBV by emphasizing the importance of dynamic processes giving rise to an approach referred to as dynamic resource-based view or dynamic capabilities. The dynamic capabilities approach which was omitted in this study opens another area for future research.

The data used did not contain information on qualitative performance issues of health objectives and in order to research those issues the qualitative study or quantitative study incorporating questionnaire should be developed. On the other hand, the dynamic evolution of efficiency concept and the usage of Malmquist productivity index (Malmquist, 1853) is an open area for further research too.

This research had used resource heterogeneity approach. It would be of interest to conduct a further research under other RBT approaches (organizing level, the conceptual, and the dynamic capability) or combination of approaches and compare the findings.

\section{References}

Adero, J.A. (2012). Influence of Tangible and Intangible Resources on the Performance of Secondary Schools in Bondo District, Kenya (Unpublished MBA Project). School of Business, University of Nairobi, Kenya.

Barney, J.B. (2007). Gaining and sustaining competitive advantage. $3^{\text {rd Edition }}$, New Jersey: Pearson Publishers.

Barney, J.B. (1991). Firm Resources and Sustained Competitive Advantage. Journal of Management, 17(1), 99-120.

Barney, J.B. (1995). Looking Inside for Competitive Advantage. Academy of Management Executive, 9(4), 49-61.

Carmeli, A. and Tishler, A. (2004). Relationship between Intangible Organizational Elements and Performance. A Case of Local Authorities in Israel. Strategic Management Journal, 25(13), 1237-1278.

Collis, O.J and Montgomery, C.A. (1995).Competing on Resources: Strategy In The 1900s.Harvard business review, 73(4), 118-128.

Crook, Ketchen, Combs and Tood(2008).Strategic Resources and Performance: A Metanalysis. Strategic Management Journal, 29(11), 1141-1154.

Dess, G., Gregory (2008).Strategic Management: Texts and Cases. USA: Mc Graw-Hill Irwin. Government of Kenya (2010). The Constitution of Kenya 2010. Nairobi: Government Press.

Government of Kenya (2010). The Constitution of Kenya 2010. Nairobi: Government Press.

Grant, R.M. (2005).Contemporary Strategic Analysis, $5^{\text {th }}$ Edition.Boston: MA. BlackWell.

Gruber, M., Heinmann, F., Bretel and Hungeling, S. (2010). Configuration of Resources, Capabilities and their Performance Implications: An Explanatory Study of Technological Ventures. Wiley and Sons Limited.

Johnson, Scholes and Whittington (2008). Exploring Corporate Strategy: Texts and Cases, $8^{\text {th }}$ Edition. USA: Oxford Publishers.

Kapelko, M., (2006) Evaluating Efficiency in the Framework of Resource-Based View of The Firm. Evidence from Polish and Spanish Textile and Clothing Industry. MBA Project, University of Australia.

Kaplan, R. and Norton (1992). The Balanced Scorecard-Measures that Drive Performance. Harvard Business Review, 70(1), 71-79.

Kaplan, R. and Norton, D. (2001). The Strategy Focused Organization. Boston: Harvard Business School Press.

Kombo, D. and Tromp, D. (2006). Proposal and Thesis Writing an Introduction.1 Edition. Africa: Pauline Publications.

Kothari, C.R. (2004). Research Methodology Methods and Techniques. $2^{\text {nd }}$ Edition.New Delhi: New Age. Ministry of Health. Kenya Health at a Glance (2012). Nairobi: Government Press. 
Ministry of Economic Planning. Kenya Demographic Health Survey (2008-2009). Nairobi: Government Press.

Ministry of Health. Kenya Health sector Policy Framework (2012-2030). Nairobi:Government Press.

Ministry of Health. Kenya Health Sector Strategic Plan (2013-2017). Nairobi: Government Press.

Liu, L., Timohty. V. and Gao, Y.(2010). Approaches of Resources -Based View: Empirical Research in Banking. International Journal of Applied Economics and Finance, 4(4), 230-241.

Newbert, S. (2007): "Empirical Research on the Resource Based View of the Firm, an Assessment and Suggestions for Future Research. Strategic Management Journal, 28, (2), 121-146.

Penrose, E. (1959). The Theory of the Growth of the Firm. $1^{\text {st }}$ Edition. UK: Oxford University Press, John Wiley and Sons, Inc.

Penrose, E. (1995). The Theory of the Growth of the Firm. $3^{\text {rd }}$ Edition. UK: Oxford University Press.

Pearce, J.A Richard, B. and Robinson (2010). Strategic Management: Formulation, Implementation, and Control. $14^{\text {th }}$ Edition. USA: MC Graw Hill.

Porter, M.E. (1985), Competitive Advantage: Creating and Sustaining Superior Performance. $3^{\text {rd }}$ Edition. London: Free Press.

Teece, D.J. (2000). Managing Intellectual Capital: Organizational Strategic, \& $\quad$ Policy Dimension. $1^{\text {st }}$ Edition. New York: Oxford University Press.

Tuan, P.T. and Takayashi, Y. (2009). Resources, Organizational Capabilities andPerformance: Some Empirical Evidence from Vietnams Supporting Industries.

Thompson, A.A, Stickland, and Gamble, J. (2007). Crafting And Executing Strategy: The Quest for Competitive Advantage: Concepts and Cases. $15^{\text {th }}$ Edition. US: Inc. Oxford Publishers.

Sheehan, N.T. and N.J Foss. (2007). Enhancing the Prescriptiveness of the Resources- Based View through Porterian Activity Analysis. Management Decision,45(3), 450-461.

Wernerfelt, B.A (1984). Resource Based View of the Firm. Strategic Management Journal, 29(2), 171180. 